\title{
EL PODER JUDICIAL Y LA CONSTITUCION DE 1979
}

Carlos Montoya Anguerry

La Constitución establece, entre otros aspectos, la organización y las funciones de los Poderes del Estado. Es evidente que las normas relativas a esa organización. expresan el criterio que los autores tienen acerca de la existencia y funcionalidad de esos Podres y refleja, además y sobretodo, su particular visión del pais en conjunto, no tanto en su realidad geográfica. como en sus dimensiones humanas y sociales.

Al interior de esta primera reflexión, se constata la existencia de un enfrentamiento entre dos puntos de vista discordantes: de un lado, una visión estática de los Poderes y del país; y de otro, una visión dinámica, esto es, profundizada al interior de esas entidades.

Se trata de preguntarse, en otras palabras, acerca del criterio que ha impreso el legislador en la decisión de las normas constitucionales relativas al Poder Judicial y, en términos generales. del país. Esta es una cuestión que no puede analizarse de una manera superficial y que exige una investigación profunda que merece una deđicación mayor. Pero existen en nuestra formación. algunos elementos de juicio que permiten una aproximación a la dilucidación del enfrentamiento entre los criterios referidos.

\section{La gratuidad de la justicia}

Uno de esos elementos de juicio es la separación que existe entre la realidad del Poder Judicial en funcionamiento y el concepto que del mismo tienen los legisladores. Un somero análisis de las normas constitucionales relativas a ese Poder, da por resultado la comprobación de que la realidad del mismo no se ha tomado en cuenta, ni se ha formulado una aproximación al conocimiento y regulación de esa situación. Se ha elaborado, por contrario, un Poder Judicial abstracto, estático, repitiendo en su mayor parte, las disposiciones de la Constitución de 1933, sin incorporar experiencias que resultan de un examen de la función que ha cumplido hasta la fecha.

En particular, no se ha dado importancia a una situación evidente para todos: el alto costo de la justicia para quienes tienen que acceder a ella. Un juicio, en la actualidad, es un problema económico; y la cuestión de fondo, esto es. el derecho desconocido o violado, pierde su dimensión frente a lo que cuesta en dinero. la reclamación en juicio.

El legislador ha prescindido de esta situación, no obstante que tiene o ha tenido conocimierito de la mìsma. Esta actitud significa un desconocimiento intencional del problema o, lo que es lo mismo, una tácita consideración de que ese problema no tiene importancia. por lo que no constituve elemento de decisión constitucional. Si el litigante puede o no sostener un juicio para reclamar 
un derecho, es una cuestión ajena totalmente a la estructura legal que organiza el Poder Judicial, no es problema que deba ser objeto de la regulación constitucional.

Se ha dicho que esta crítica carece de sustento, pues generalmente quien reclama un derecho o tiene los medios necesarios para iniciar un litigio o está en la obligación de solventar el juicio en base, precisamente, del beneficio económico que al final obtendrá. Se ha dicho, igualmente, que no corresponde al Estado pagar el costo de los juicios para defender o restablecer los derechos de quienes tienen medios económicos. Y se ha argüído, asimismo, que todo servicio público exige el aporte del particular, como sucede aún en aspectos más vitales como la prestación de los servicios asistenciales médico-farmacéuticos.

Entendemos que esta crítica refiere un criterio de proyección de los males que aquejan a otras esferas de la actividad del Estado, pero que no tiene validez alguna si se examina el fenómeno en si mismo. Desde esta perspectiva es necesario, en primer lugar, señalar que el servicio de la administración de justicia tiene evidentemente un costo, resultante del sostenimiento del aparato judicial en remuneraciones, locales, útiles y demás; pero este costo debe ser asumido por el Estado, al igual que los otros servicios destinados a la satisfacción de necesidades vitales de la población. El referir ese costo o trasladarlo a los particulares, es anteponer un criterio pragmático a otro de mayor jerarquía que es la función jurisdiccional.

Por otra parte, la realidad está proporcionando una certeza que es necesario destacar y es que el Estado corre ya con algunos de los costos de la administración de justicia, como las remuneraciones de los jueces y del personal administrativo, la construcciôn y equipamientos de locales, etcétera. De manera que cuando se dice y con razón que la justicia es costosa para el particular, se está haciendo referencia a otros factores, dentro de los cuales cabe señalar la necesaria intervención de profesionales, auxiliares y personal no remunerado por el Estado.

Otras dos constataciones deben ser expuestas: la primera que las partes en litigio no se encuentran en igualdad de condiciones económicas. Siempre se da el caso de que una de las partes cuenta con mayores recursos y esto, dentro del sistema de justicia formal que tenemos, orienta hacia soluciones injustas, sin mencionar la acción de presiones que intentan doblegar al personal de la administración de justicia. Luego predomina entre los litigantes de recursos, la consideración de su poderio económico, suficiente para empapelar al contrario y hacer alarde de ello. Esta desigualdad puede y debe ser criterio de decisión normativa y en ese sentido, el declarar que la justicia es gratuita destruye esa desigualdad pues el servicio será igual para todos. Es cierto que clandestinamente el poder económico pretenderá y logrará ventajas a pesar de toda declaración en contrario, pero estaremos en presencia de un hipofenómeno, de una realidad extra y aún contralegem, objeto de persecución. 
La segunda consiste en la expresa y definida actitud de la Corte Suprema de la República dirigida hacia la gratuidad de la justicia, por lo menos en uno de sus aspectos. En efecto, por acuerdo de la Sala Plena de Justicia en el Arancel de Derechos Judiciales se ha declarado la gratuidad de las diligencias de inspección ocular a cargo de los jueces de primera instancia; esta decisión posibilita, al menos teóricamente que el litigante de escasos recursos económicos, puede ac tuar esa clase de pruebas que anteriormente, por el costo elevado de la misma, estaba muy lejos de ser realizada(1)

\section{El acceso cerrado}

Planteado el anhelo de la gratuidad de la justicia, debe mencionarse otra proyección del mismo problema económico. Consiste éste en el acceso cerrado a las clases o estratos sociales desvalidos económicamente. Las personas que pertenecen a ellos, no pueden literalmente, alcanzar justicia para la solución de sus conflictos jurídicos entre sí y frente a los poderosos. La justicia, aún la formal, es un ente lejano para ellos, que es imposible de alcanzar. Es, al contrario, la injusticia lo ordinario, lo que forma parte de su vida y que se sufre calladamente, con resignación, o a través de estallidos de impotencia.

La mujer que siendo casada o madre soltera tiene el derecho de accionar para el pago de una pensión alimenticia, no cuenta entre sus posibilidades la de iniciar juicio de alimentos. Ni tiene los medios económicos necesarios ni el tiempo indispensable para esta aventura en que consiste un juicio. Su personal decisión es el trabajo, no utilizar el aparto judicial. Y como este caso, muchos otros en los que nítidamente se observa esa situación de lejanía del Poder Judicial de los problemas de las personas económicamente pobres. Los que pertenecen a este Poder tienen más de una experiencia en ese sentido, pues no son pocas las veces que una persona humilde se acerca a inquirir por la forma de resolver un problema que le aqueja, creyendo que el Juez va a prestar oídos directamente a su inquietud, y recibe una respuesta inevitable: debe ocurrir a juicio y para sostenerlo debe contar con medios económicos.

Un paliativo a esta situación de graves repercusiones es el llamado beneficio de pobreza establecido en el ordenamiento procesal y también la creación de los Consultorios Gratuitos tanto los dirigidos por algunos Colegios de Abogados como por algunos Programas Académicos de Derecho de las universidades. Pero adviértase que se trata de remedios consagrados en normas legales de inferior jerarquía a la Constitución. Esta se ha limitado a establecer que el Estado provee la defensa gratuita a las personas de escasos recursos (Art. 233. Inc. 9o.)

(1) Esta actitud fue contradicha, posteriormente con la creación de la Tasa Judicial conforme al Decreto Ley pertinente. Pero se formuló este en forma excepcional para aliviar una crítica situación económica. 
Después de haber analizado tan someramente los problemas de la graujdad de la justicia y del acceso cerrado, cabe aún mencionar otra situación tan o más importante que las anteriores. Es ia incongruencia que contienen las normas constitucionales sobre el Poder Judicial, pues no obstante contener la solemne declaración de que la potestad de administrar justicia emana del pueblo - Artículo 232 - sin embargo no se ha elaborado ni establecido un sistema que permita la intervención directa del pueblo en la función jurisdiccional. limitándose esa función a los juzgados y tribunales especializados o profesionalizados.

Puede decirse, con beneficio de inventario, que en los legisladores, ha primado el criterio formal de la justicia, según el cual ésta se desarrolla en términos $y$ modos tan abstractos que solamente puede ser manejada por profesionales. Pero existen muchas situaciones de la vida diaria. traducidas en términos juridicos, que se resuelven tan prosaicamente como se generan, sobre la base de la aplicación del sentido común. de la experiencia personal y en ellas cabe la presencia del propio pueblo para su resolución.

En esos mismos problemas, la solución que proporciona el Poder Judicial formal, entrabado por el uso de conceptos $y$ terminologia abstractos, resulta postiza y hasta extraña a la misma realidad. Este resultado es posible también por la imposibilidad objetiva que tiene el Juez de conocer la verdadera dimensión del problema sometido a su decisión, imposibilidad que nace del sistema procesal mismo en el que no se realiza plenamente la inmediatez.

La existencia de Juzgados de Paz No Letrados es un intento o aproximación a este anhelo de participación directa del pueblo en la administración de justicia. Pero este escalón de la justicia formal, se encuentra en estado de abandono y en situación de crisis. Los legisladores han debido tomar conocimiento del problema y fortalecer esa y cualquier otra forma de esa participación directa, en un intento de llevar a sus consecuencias la declaración que contiene el citado articulo 232 de la Constitución.

\section{El rol del Poder Judicial}

El Poder Judicial aparentemente resuelve problemas particulares, contenidos en los expedientes formados en base de demandas y denuncias, dando la impresión de no tener repercusión alguna en la problemática general del país. Esta impresión es, desde luego, falsa, pues a través de la resolución del caso particular, el Poder Judicial asume una función reguladora del orden jurídico general.

La Constinución de 1979, sin embargo, no ha reelaborado este rol de la administración de justicia. No ha interesado a los autores el contenido de este rol, es decir, cómo debe el Poder Judicial asumir un papel protagónico frente a 
los grandes problemas nacionales. Es aqui en donde puede observarse el criterio estático que contienen las normas constitucionales, respecto de la administración de justicia.

Un ejemplo puede ilustrar el planteamiento de la situación anterior. La ley de Reforma Agraria, número 15,037 promulgada el 24 de mayo de 1964, en sus aspectos judiciales fue de conocimiento del fuero común. Frente a ella y no obstante tratarse de una ley emanada del Parlamento, que contaba con el consenso nacional y aún internacional (aunque con severas criticas), el Poder Judicial adoptó una actitud especial; los jueces tomaron la referida legislación como si fuera un problema formal, de indole civilista, e introduciendo criterios conservadores tendientes a la protección del derecho de propiedad(1)

Esta situación provocó una reacción: la creación del fuero agrario, formulada por el gobierno de facto posterior y mediante el Decreto Ley 17716. Los resultados de esta medida fueron conocidos de inmediato, pues el Tribunal Agrario y los Jueces de Tierras asumieron una actitud distinta, demostrándose así que no solamente se había producido un desmembramiento del Poder Judicial en su estructura, sino también en el criterio dinámico, finalista, de la aplicación del tex to legal promulgado. Es evidente que este fenómeno está sujeto a la crítica y a la calificación de positiva o negativa, pero su producción interesa para los efectos de este breve comentario.

La experiencia extraída de la historia reciente, no ha sido recogida por los legisladores, quienes tácitamente han decidido desconocer la actitud del Juez frente a los problemas del proceso peruano, frente a la problemática más profunda y grave del país.

Si se reconoce que el Poder Judicial y, en particular el Juez tiene un rol protagónico frente a los problemas nacionales, debió formularse una definición constitucional del mismo para propiciar una actitud definida del juez que no está, ni puede, ni debe estar al margen. El Juez por propia función está colocado en el centro neurálgico de la vida social y no puede permanecer pasiva ni menos negativamente frente a las grandes decisiones políticas tendientes a la

(1) la afirmación de que el Poder Judicial es conservador no solamente ha sido formulada por los entendidos desde fuera del Poder referido, sino también ha sido reconocida por las autoridades del mismo. El Presidente de la Corte Suprema de la República, Dr. Domingo García Rada así lo reconoció en su artículo sobre el Poder Judicial en el siglo XX, contenido en el libro "Visión del Perú en el Siglo XX". Studium. Lima 1963: "Encierra peligro conceder esta facultad al Poder Judicial (se refiere a la declaración de inconstitucionalidad de las leyes) que, por esencia, es conservador y puede dificultar el desarrollo del país en el campo laboral, así como impedir las reformas sociales, desconociendo instituciones nuevas o frustrando los avances que confieren sentido social a la propiedad". 
renovación de las estructuras políticas, económicas y sociales. Esta renovación es el signo impreso de esta etapa de la vida nacional, por lo tanto, el Juez debe asumir una actitud especial.

Puede decirse, en consecuencia, que al no haberse propuesto reformas estructurales en la Constitución (en virtud de una concepción formalista de la misma), se ha dejado al Poder Judicial en un rincón, para que cumpla una función abstracta, asumiendo que al interior del Estado no existen problemas profundos y que los conflictos particulares que resuelve ese Poder no tienen repercusión alguna en la sociedad.

Debe agregarse a lo dicho que en las etapas anteriores al debate constitucional, se formuló un planteamiento concreto que no llegó a plasmarse, según el cual, el Poder Judicial y, en particular, el Juez, debía tomar en cuenta las grandes decisiones de política económica-social y adecuar sus decisiones a esos fines de interés nacional.

\section{La justicia, la ley y la realidad}

Al interior de su propia función, el Juez observa una serie de problemas suscitados en la aplicación de las leyes y entre ellos, la existencia y vigencia de leyes caducas o injustas tanto en los aspectos sustantivos como procesales. Frente a ellas, el juez peruano adopta dos actitudes: o asume una posición legalista, dejando de lado la realidad del conflicto que resuelve y que es un supuesto distinto del que sustentó la ley antigua; o asume una posición moderna, no legalista, para encontrar un camino hacia la justicia.

En ambas alternativas, el riesgo de la justicia es grande, pues en la primera, se resiente la realidad con la mecánica aplicación de una norma y en la segunda, se resiente la estabilidad del juez, pues sus decisiones serán incomprendidas por quienes, con criterio conservador y legalista, están interesados en sostener un rígido esquema normativo compuesto de leyes sagradas y por lo mismo intocables.

La Constitución ha desconocido esta situación de tan graves proyecciones, pues parece que sus autores consideran que la función jurisdiccional es un simple juego de normas o conceptos, y no un juego de intereses concretos, vitales(2).

El juez debe aplicar la ley, es la norma genérica, ineludible; la función creadora del juzgador, reconocida por la doctrina más reciente, no ha sido consagrada en el ordenamiento constitucional.

(2) Hay que citar al efecto el Art. 233, inc. 6o. de la Constitución de 1979, así como el Art XXI del T. Preliminar del C.C. y el Art. 23, inc. a) de la ley Orgánica del Poder Judjcial. 
En el intento de ofrecer una solución a la situación planteada y tomando como base una propuesta formulada en un anteproyecto, puede mencionarse la interesante alternativa de permitir que el Juez, en los casos especiales de conflicto entre la realidad y la ley, pueda resolver creando la norma para el caso particular, adoptando una decisión excepcional extra-legem, debidamente fundamentada y explicada.

Esta facultad se encuentra en parte reconocida por la nueva Constitución, en cuanto regula la situación que se produce cuando hay defecto o deficiencia de la ley, pues el Art. 233, inciso sexto, dispone que deben aplicarse ios principios generales del derecho y, preferentemente, los que inspiran el derecho peruano. Pero la situación que se plantea es distinta, ya que se refiere no a la deficiencia de la ley sino al resultado notoriamente injusto de la ley vigente. En este caso el Juez, conforme al sistema imperante y recogido por la Constitución, no tiene más que aplicar la literalidad de la norma o correr el riesgo de una sanción disciplinaria. Pero si la Constitución, tomando conocimiento de esta realidad, permitiera alguna flexibilidad al Juez para que, explicando la situación, definiera el conflicto en términos de justicia (y no de legalismo), nos encontrariamos con un ordenamiento constitucional dinámico, atento a la propia realidad que regula.

Otorgada la facultad indicada, sería el caso de regularla mediante normas de control, como la consulta obligada al superior jerárquico, o normas restrictivas de la facultad a casos especialísimos (que son los que precisamente motivan este comentario) o, finalmente, creando conceptos o definiciones (aunque relativos) de los llamados casos "límite".

Es de advertir que una más lúcida labor judicial, sobre la base de una toma de conciencia de la verdadera función jurisdiccional, permite actualmente a los jueces aproximarse más a la realidad y a la justicia. Pero esta actitud es aún excepcional, pues lo corriente es la frialdad del texto legal, la rigurosidad aparentemente lógica del razonamiento judicial, con prescindencia de la realidad, con desconocimiento de los efectos reales de una resolución judicial. La constitución no ha asumido el problema.

\section{Aspectos positivos}

Las reflexiones anteriores no constituyen ideas originales del autor, sino de muchas personas, sobre todo de quienes integran el Poder Judicial y que fueron y son expuestas en comisiones, conversaciones, seminarios, y demás actividades de esta índole. Constituyen planteamientos de problemas que preocupan hondamente a los jueces y que esperan una mejor dilucidación y tratamiento para la búsqueda de soluciones positivas.

No ha sido tampoco el ánimo el de desconocer la importancia del Capítulo dedicado a la organización y funcionamiento del Poder Judicial que 
contiene la Constitución de 1979, pues consagra aspectos sumamente positivos como el de conferir carácter constitucional a las garantías de la administración de justicia que estaban reconocidas anteriormente, en leyes de inferior jerarquía. Así mismo, es realmente destacable la preocupación por la estabilidad del Juez al reconocer requisitos especiales, particularmente en cuanto a la edad máxima de los jueces y que no son ya objeto de normas de inferior categoría, para evitar los abusos del poder. Finalmente, puede anotarse también la preocupación por resolver los problemas económicos del Poder Judicial al establecer un porcentaje del Presupuesto en favor de esa organización.

Estos aspectos merecen también ser comentados y lo serán, seguramente, por los entendidos en esta difícil estructura del Estado que es el Poder Judicial. 